\title{
Experimental Investigation of Wave-Induced Ship Hydroelastic Vibrations by Large-Scale Model Measurement in Coastal Waves
}

\author{
Jialong Jiao, Huilong Ren, Shuzheng Sun, and Christiaan Adika Adenya \\ College of Shipbuilding Engineering, Harbin Engineering University, Harbin 150001, China \\ Correspondence should be addressed to Huilong Ren; renhuilong@263.net
}

Received 8 October 2015; Accepted 31 January 2016

Academic Editor: Jörg Wallaschek

Copyright (C) 2016 Jialong Jiao et al. This is an open access article distributed under the Creative Commons Attribution License, which permits unrestricted use, distribution, and reproduction in any medium, provided the original work is properly cited.

\begin{abstract}
Ship hydroelastic vibration is an issue involving mutual interactions among inertial, hydrodynamic, and elastic forces. The conventional laboratory tests for wave-induced hydroelastic vibrations of ships are performed in tank conditions. An alternative approach to the conventional laboratory basin measurement, proposed in this paper, is to perform tests by large-scale model measurement in real sea waves. In order to perform this kind of novel experimental measurement, a large-scale free running model and the experiment scheme are proposed and introduced. The proposed testing methodology is quite general and applicable to a wide range of ship hydrodynamic experimental research. The testing procedure is presented by illustrating a 5-hour voyage trial of the large-scale model carried out at Huludao harbor of China in August 2015. Hammer tests were performed to identify the natural frequencies of the ship model at the beginning of the tests. Then a series of tests under different sailing conditions were carried out to investigate the vibrational characteristics of the model. As a postvoyage analysis, load, pressure, acceleration, and motion responses of the model are studied with respect to different time durations based on the measured data.
\end{abstract}

\section{Introduction}

In the recent decades, ships have become larger and faster due to the world globalization and the development requirements. As a result, the natural frequencies of large ships have become lower and may often fall into the range of wave encounter frequencies even in a common sea state [1]. Therefore, simulations of hydroelastic vibrations of large ships should be performed to accurately predict the wave-induced loads of ships [2].

Hydroelastic mechanics is a branch of ship structural mechanics, which considers both ship hydrodynamic force and hull structural elastic force [3]. Since ship hydroelastic vibration problems-involving the mutual interaction of a complex shaped elastic hull with fluid and free surfaceare quite complex and cannot be satisfactorily processed by numerical and analytical approaches, physical simulation tests constitute an indispensable approach in the investigation of ship hydroelasticity [4]. Generally speaking, there are two different kinds of models for performing tests for hydroelastic vibrational responses: monoblock model and segmented model $[5,6]$. In the former model, a material of proper Young modulus which is much smaller than steel and of the same Poisson ratio as steel is used to build the model hull in order to make the stiffness of model similar to ship prototype [7]. The latter model, that is, segmented model, is connected by a continuous compliant backbone, from which the sectional loads and vibrations responses of the model hull can be measured [8]. On the other hand, the rare material in the first model is quite expensive and is not easy to be operated at model manufacture process. Therefore, the latter testing approach is a more popular choice compared with the former.

The conventional laboratory segmented models for hydroelastic vibration responses are towed in the tank [9-11]. Usually the models are relatively small and the waves are generated by wave makers. It is known that the scale effects and boundary wall effects must be considered while designing and performing tank tests. The waves generated by wave makers are unidirectional, artificial, and pseudo-random. Furthermore, the six degrees of freedom motions of the model in the tank are usually measured by mechanical seakeeping instrument, which connects the model using its heave sticks. However, the heave sticks fixed on the model may restrict 
the model's freedom of motions in some sense. In summary, the above statements reflect some of the challenges of the conventional tank model tests.

In fact, the real sea conditions, where ships sail, are quite different from those simulated in the tank. In the sea there exist wave diffraction, refraction, and breaking, as well as the associated effects caused by winds and currents. Sea waves spread along a dominant direction with components from different directions superimposed onto one another, while the tank waves are usually unidirectional. Although a few novel tank facilities allow for the generation of two directions crossed irregular waves [12], the waves generated are still more or less different from the actual sea waves. It is considered that full-scale ship sea trial measurement reflects what really happens on the ship. However, the data acquisition is quite difficult since the weather and wave states are uncontrollable. Moreover, the extreme high sea states desired for investigation are rarely suffered by a full-scale large ship.

A new alternative approach to the laboratory basin measurement and full-scale sea measurement, introduced in this paper, is to perform tests by large-scale models in real sea conditions [13-15]. The measurements are carried out in shortcrested, directional spreading, and wind-generated sea waves. The scale effects can be reduced by testing relatively larger scale models. The large-scale models can be tested with the equipment of superstructures and appendages, thus the wind and current associated effects are taken into account. The tests can be carried out at any arbitrary heading angle. In a word, this testing condition can be regarded as more realistic compared with the laboratory basin condition. However, there also exist disadvantages regarding the proposed approach, such as the fact that the sea wave conditions cannot be controlled and thus the trial procedure lasts a long time waiting for the expected wave conditions.

The characteristics of hydroelastic vibrations and bowflare slamming of a small-scale model in regular waves have already been studied through laboratory tank tests, which can be found in the authors' previous work [16]. In the present work, a large-scale model, corresponding to the same prototype as that of the small-scale model, was designed and manufactured to allow for the measurement of wave-induced hydroelastic vibrations and slamming experienced in coastal waves.

In this paper, the large-scale model structural design and experimental system are introduced first. Then, a 5-hour voyage trial performed at Huludao harbor of China in August 26, 2015, is presented. Finally, the hydroelastic vibrational and bow impact characteristics of the large-scale model are described and analyzed from different terms based on the experimental results.

\section{Experimental Design}

2.1. Hull Structural Design. To investigate the hydroelastic vibrational behavior of a large ship, a large-scale segmented model hull was designed and built. The principal parameters of the prototype and model are listed in Table 1, where VCG denotes vertical center of gravity (COG), LCG denotes
TABle 1: Principal parameters.

\begin{tabular}{lcc}
\hline Description & Ship prototype & Model hull \\
\hline Scale & $1 / 1$ & $1 / 25$ \\
Length overall $(\mathrm{m})$ & 313 & 12.52 \\
Length waterline $(\mathrm{m})$ & 292 & 11.68 \\
Moulded breadth $(\mathrm{m})$ & 39.5 & 1.58 \\
Depth $(\mathrm{m})$ & 25.5 & 1.02 \\
Draft $(\mathrm{m})$ & 10 & 0.40 \\
Displacement $(\mathrm{t})$ & 71875 & 4.6 \\
VCG from BL $(\mathrm{m})$ & 16 & 0.64 \\
LCG from AP $(\mathrm{m})$ & 140.5 & 5.62 \\
\hline
\end{tabular}

longitudinal COG, BL denotes baseline, and AP denotes aft perpendicular.

The model hull was constructed by fiberglass reinforced plastic (FRP) material. A continuous backbone beam was installed at the mean neutral axis height of the segmented model to connect the segments. The ship model was designed to have 20 stations in total, with station 0 at bow area and station 20 at aft area. The model hull was divided into seven independent segments by using the $2 \mathrm{nd}, 4 \mathrm{th}, \ldots, 12$ th divisions at the manufacture stage. Sectional loads at the six cut divisions are measured by using unidirectional strain sensors mounted on the backbone surfaces. The monolithic large space from the 12th station to 20th station at aft area is used for housing propulsion system. General arrangements of the ship model structure and the onboard experimental apparatus are shown schematically in Figure 1.

The pressure response behaviors of flare impact and bottom impact at bow area are studied in particular [17]. Three pressure gauges intended to measure the bow-flare impact pressure and one intended to measure the bottom fluctuating pressure are disposed at the center line of bow area, whose positions can be seen in Figure 2. The pressure gauges have a range of $100 \mathrm{kPa}$ and an accuracy of $10 \mathrm{~Pa}$ for measurement. The sampling frequency of pressure gauges was set at $100 \mathrm{~Hz}$ during the measurements.

Photographs of the large-scale model are illustrated in Figure 3. Figure 3(a) shows the large-scale model onshore before the experimental activities at Huludao harbor. Figure 3(b) shows the backbone beam and its fixing instruments after model assembly in the laboratory of the Institute of Naval Architecture and Ocean Engineering Mechanics (INOM) of Harbin Engineering University (HEU), where the model was assembled and debugged.

2.2. Backbone System. Steel backbone beam with rectangular tubular structure was designed for the model to allow for the measurement of ship wave loads. The configuration and parameters of cross section of the backbone beam were determined to satisfy the stiffness distribution and two-node vertical vibrational natural frequency of the model hull. The inner wall dimensions for width $L$ and height $H$ of the backbone remain unchanged. The backbone was however made with different thicknesses $t$ and $d$ at different sections so as to meet the stiffness distribution demand. Strain gauges of 


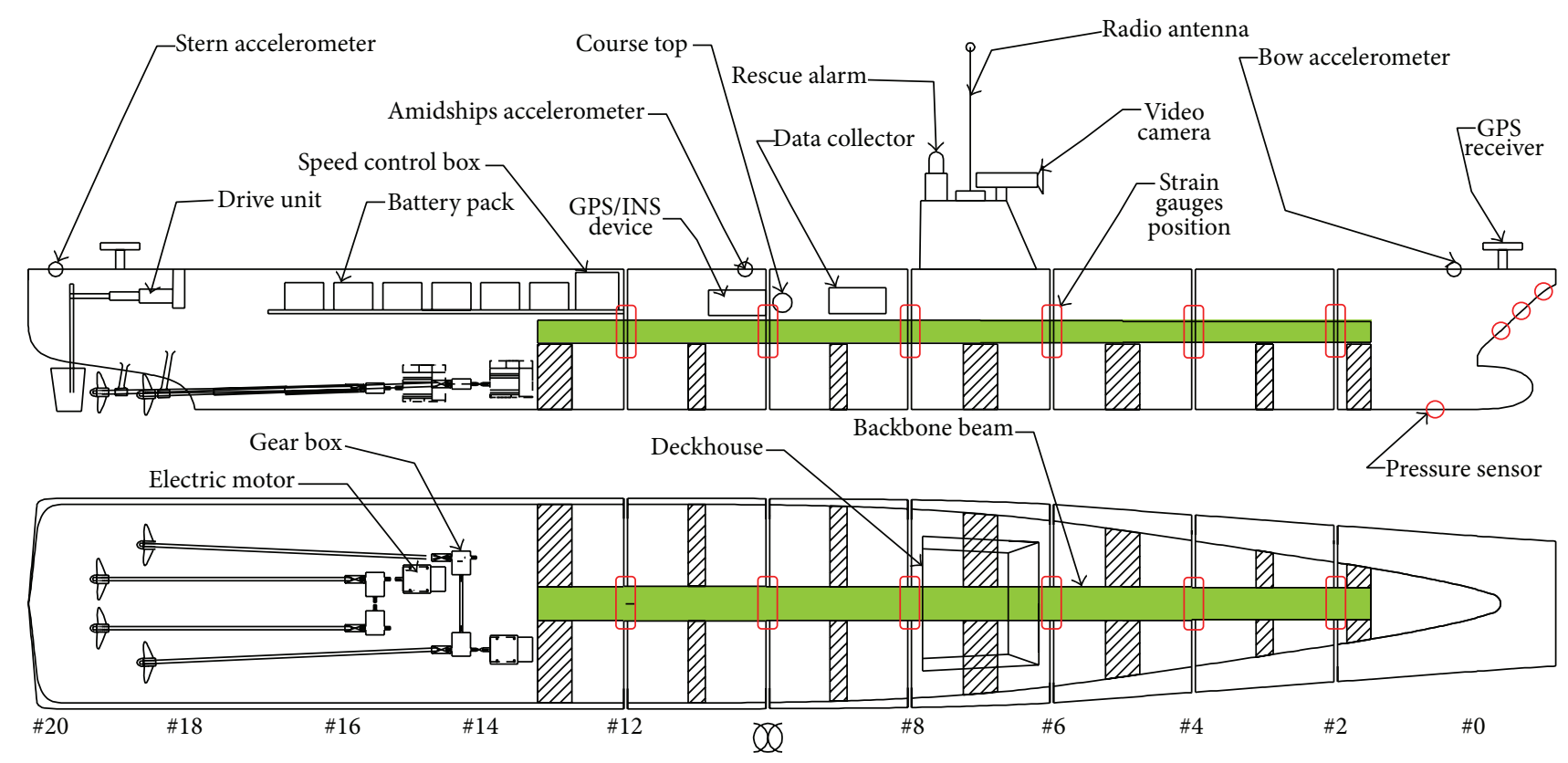

FIGURE 1: Model equipment.

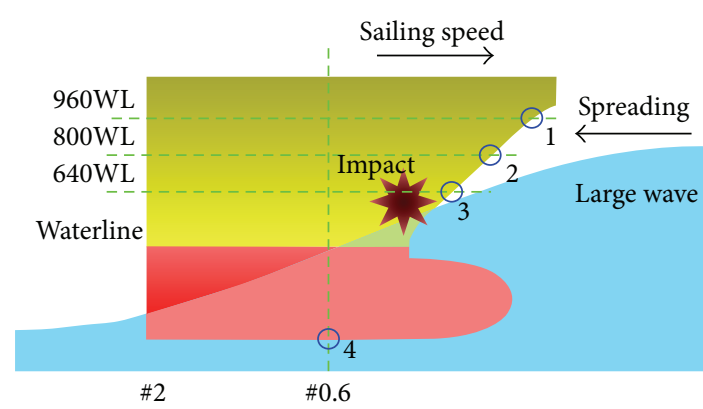

FIGURE 2: Sketch of bow-flare impact model.

full-bridge circuit were mounted on the backbone surfaces at $2 \mathrm{nd}, 4$ th $, \ldots, 12$ th stations in order to measure sectional vertical bending moment (VBM) and horizontal bending moment (HBM) acting on the model induced by waves. The sectional dimensions of the backbone and the arrangement of full-bridge strain gauges on the backbone surfaces are shown schematically in Figure 4, where $V 1 \sim V 4$ are strain gauges for VBM measurement and $H 1 \sim H 4$ are strain gauges for HBM measurement. The strain gauges have a range of $2000 \mathrm{MPa}$ and a measurement accuracy of $0.001 \mathrm{MPa}$. The sampling frequency was set at $50 \mathrm{~Hz}$ during the tests. The comparisons of the expected value and design value of bending moments of inertia distributions along the model length are shown in Figure 5.

Fixing plates were adopted between each pair of the cut stations, that is, at the 1.5 th, $3 \mathrm{rd}, 5 \mathrm{th}, \ldots, 13$ th stations, to fix the segmented hulls on the continuous backbone beam strongly. The sketch of the ship model global vibrational system is shown in Figure 6. In this simplified diagram, the segmented hulls are regarded as mass centralized on the continuous backbone and the fluids around the hulls are regarded as added mass on the segmented hulls. The waveinduced loads are transferred to the backbone beam by the segmented hulls. The sectional loads are measured by the strain gauges located between each pair of the segmented hulls.

Since the sectional signal measured by full-bridge strain gauges is strain (stress), the corresponding bending moment can be expressed as follows:

$$
M_{m}=\frac{\sigma I}{z},
$$

where $\sigma$ denotes the measured stress, $I$ denotes the sectional moment of inertia, $z$ denotes the distance between the neutral axis and the strain gauge, and $M_{m}$ denotes the obtained bending moment corresponding to model hull.

In addition, the bending moment corresponding to ship prototype can be derived by the similitude law according to the knowledge of ship hydrodynamic experiment:

$$
M_{s}=\frac{M_{m}}{\lambda^{4}},
$$

where $M_{s}$ denotes the obtained bending moment corresponding to ship prototype and $\lambda$ denotes the model scale ratio.

The derived conversion coefficients for bending moment corresponding to model scale and full-scale are, respectively, listed in Table 2. In addition, calibration tests were also conducted on the backbone beam by applying known static loads and recording the corresponding strain values to validate the calculated conversion coefficients of model scale. The confirmatory test results are in good agreement with the calculations. 


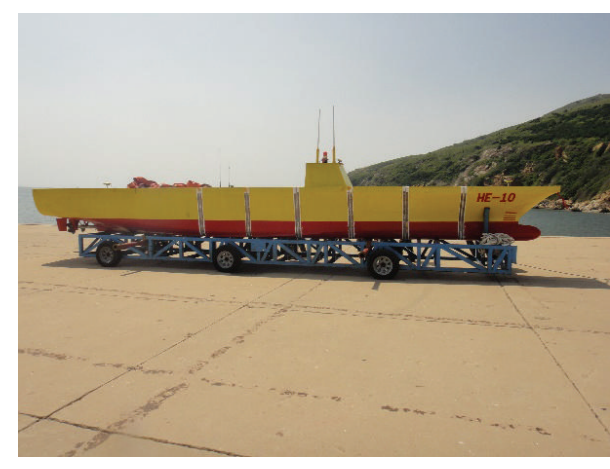

(a) Hull structure

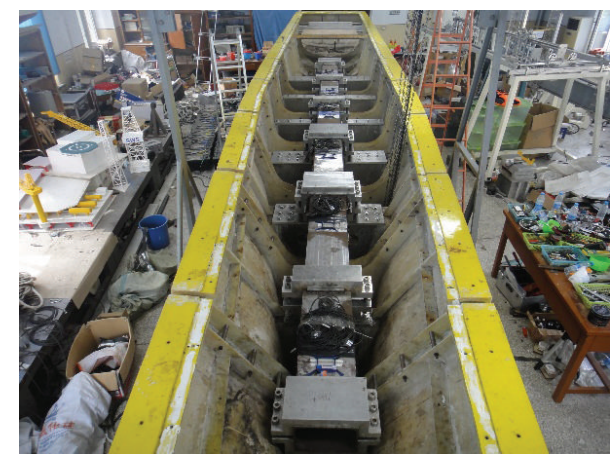

(b) Backbone system

FIGURE 3: Photographs of the large-scale model hull.

TABLE 2: Conversion coefficients.

\begin{tabular}{lcccc}
\hline Station & \multicolumn{2}{c}{ VBM } & \multicolumn{2}{c}{ HBM } \\
& $\begin{array}{c}\text { Model } \\
(\mathrm{N} \cdot \mathrm{m} / \mathrm{MPa})\end{array}$ & $\begin{array}{c}\text { Prototype } \\
(\mathrm{MN} \cdot \mathrm{m} / \mathrm{MPa})\end{array}$ & $\begin{array}{c}\text { Model } \\
(\mathrm{N} \cdot \mathrm{m} / \mathrm{MPa})\end{array}$ & $\begin{array}{c}\text { Prototype } \\
(\mathrm{MN} \cdot \mathrm{m} / \mathrm{MPa})\end{array}$ \\
\hline 2 & 428 & 167 & 443 & 173 \\
4 & 457 & 179 & 565 & 221 \\
6 & 720 & 281 & 936 & 366 \\
8 & 875 & 342 & 994 & 388 \\
10 & 899 & 351 & 1082 & 423 \\
12 & 934 & 365 & 1216 & 475 \\
\hline
\end{tabular}

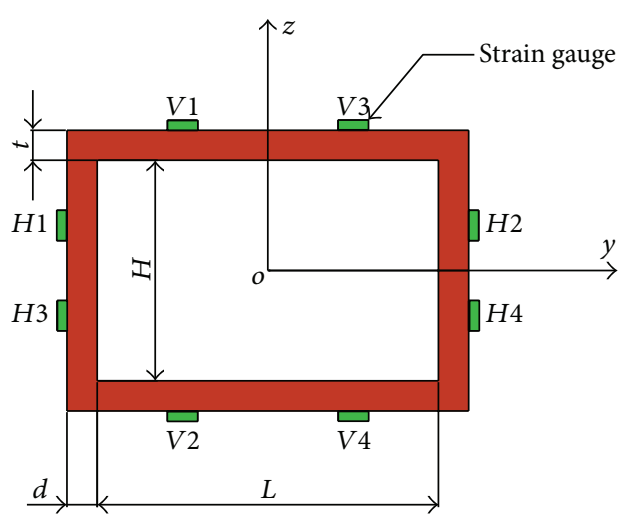

FIGURE 4: Cross section of backbone beam.

2.3. Testing System. Three ships, that is, $A, B$, and $C$, are used to allow for the execution of the experimental activities. Ship $A$ is the large-scale testing model. Ship $B$ is an auxiliary yacht which moves around $A$ but keeps a distance of about $100 \mathrm{~m}$ from $A$ during the testing measurement. Ship $C$, situated at the center of sailing trace of model ship $A$, is used for wave measurement. A crew onboard $B$ steers the model ship $A$ via radio signal to make it run at a desired speed and a desired heading angle. In addition, another crew onboard $B$ uses video camera to record the scene of sailing information of model ship $A$. Three pairs of radio stations are adopted and installed onboard of $A$ and $B$ to allow for the communications between the two ships.

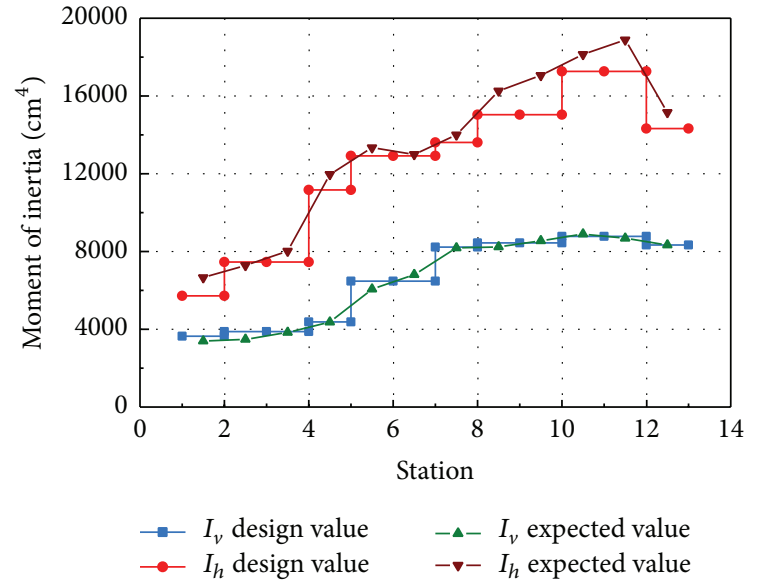

FIgURE 5: Comparison of moments of inertia.

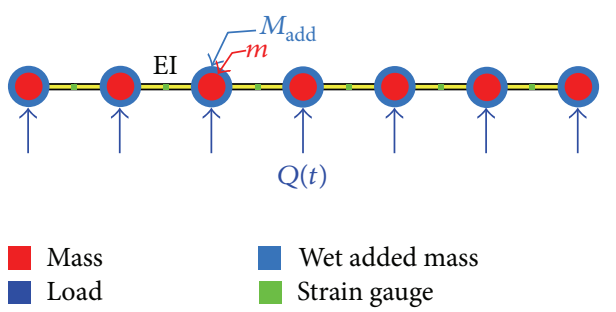

Figure 6: Sketch of the model hull global vibration system.

The radio-controlled self-propelling model ship is fully equipped with all the electronic technique apparatus which are necessary to carry out the experiments. The apparatus mainly includes GPS device, propulsion system, autopilot system, and a data recorder. Framework of the testing system is shown in Figure 7 and the subsystems are generally concluded below $[18,19]$.

The GPS/INS-aided device is utilized to measure and record the position, speeds, heading angle, and motions of the testing model $A$. Its measurement precision of heading angle is in $0.05^{\circ}$, pitch and roll angle precisions are in $0.02^{\circ}$, and three unidirectional (eastern, northern, and vertical) speed 

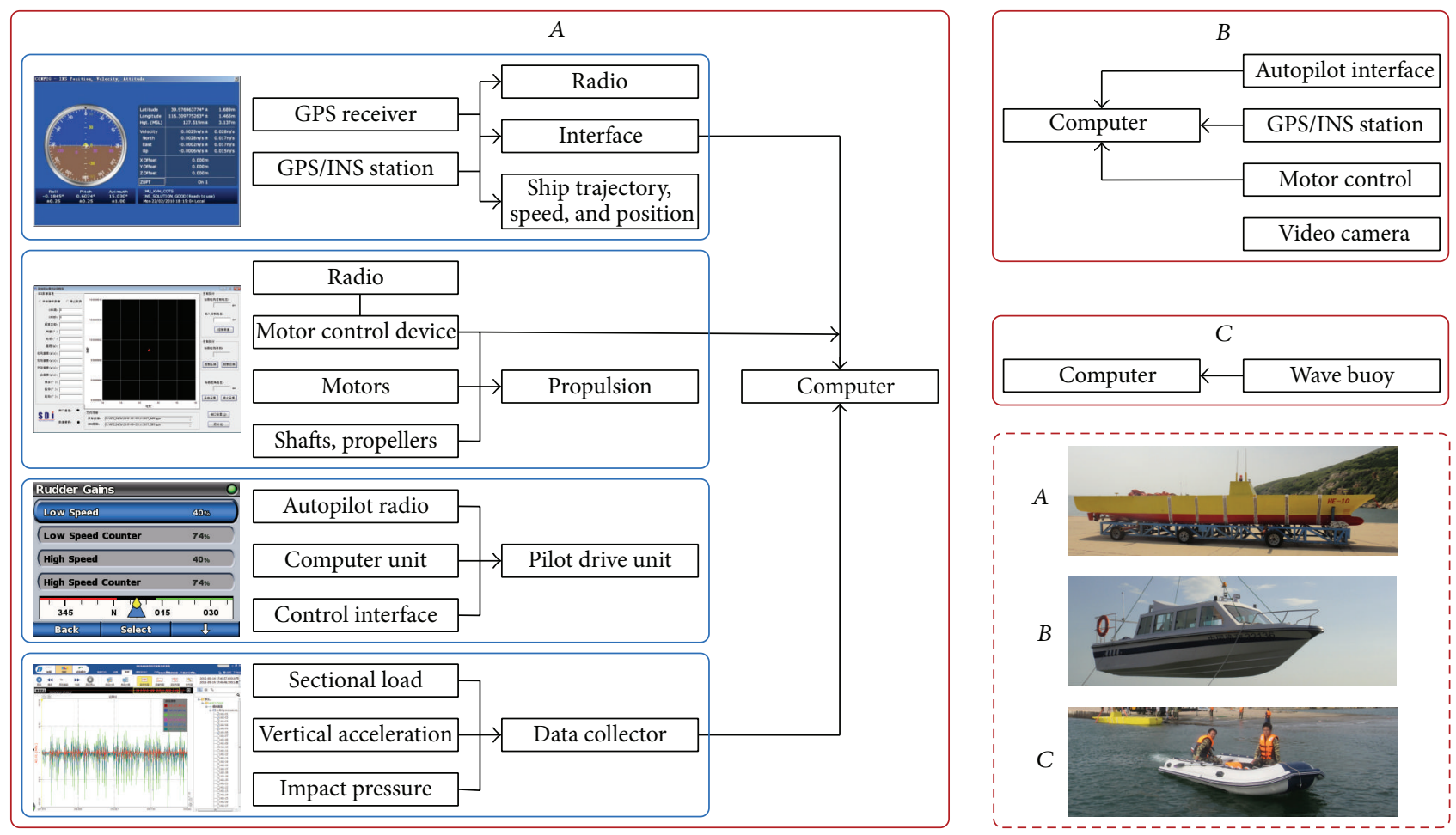

FIGURE 7: Framework of the overall testing system.

precisions are in $0.02 \mathrm{~m} / \mathrm{s}$. Data recorded by the GPS/INSaided device are transmitted to the auxiliary yacht $B$ by radio; then the laptop onboard $B$ processes and displays it to the crew.

Four screw propellers and double DC brushless electric motors are used by the model to achieve the experimental forward speeds. Each electric motor is used to drive double shafts (the inner pair or outer pair) with the help of the dedicated cross-connection gearboxes. The schematically arrangement of the propulsion mechanism can be found in Figure 1. A set of rechargeable sulfuric acid storage battery pack is adopted to provide the necessary energy to propel the ship model as well as to support all the electronic equipment.

Twin rudders were installed behind and, in alignment with, the inner propellers. A set of autopilot control system, which is the commercial production of GARMIN Company, is used to steer the model. The autopilot system is made up of four subsystems. They are the course computer unit, the electronic control unit, the drive unit, and the user control interface unit [20]. A course top is used to feedback the course of model ship in real time. The autopilot controller, supported by a GPS-unit, is based on the PID control algorithm. Model course is kept by the dedicated drive unit, which adjusts the rudder angle by its built-in hydraulic instrument. When the ship model $A$ needs to change course, the crew will input a commanded heading angle using the dedicated user control interface onboard $B$, and then the signal will be transmitted by radio and received by the control computer unit onboard $A$. Then the rudder angle will be adjusted and kept by the drive unit.
A commercial DONGHUA TEST 5902 data acquisition device is adopted to record the sectional loads, the impact pressures, and the vertical axis accelerations at bow and stern areas during the trials. The main purpose of the model tests is to measure the sectional hull girder VBM and HBM loads induced by waves. In addition, bow impact and fluctuating pressures are measured by pressure transducers. The ship sailing states and motions are measured by the aforementioned GPS/INS-aided device. Moreover, the sea waves are measured by a wave buoy.

\section{Experimental Campaign}

The field tests were conducted at the nearshore seas of Huludao, China (north longitude $40^{\circ} 66^{\prime}$, east latitude $120^{\circ} 93^{\prime}$ ) in August 2015. Figure 8 shows an aerial view of the testing field. The running route was selected at about $6 \mathrm{~km}$ away from the beach, where the water surface is large enough to execute the tests. During the tests, two video cameras (one was supported by a testing crew onboard the auxiliary yacht $B$ and the other was mounted onboard the model ship $A$ ) recorded the scenes of testing procedure from different views simultaneously. All the crew highly cooperated to ensure all the testing systems operated in a good state so that the trials could proceed smoothly and accurately.

For each set of the sailing speed under a certain sea state, the responses at six different heading angles were tested [21]. The runs were performed according to the desired run routes as illustrated in Figure 9, in which direction 1 is for head wave condition, direction 2 is for following wave condition, 


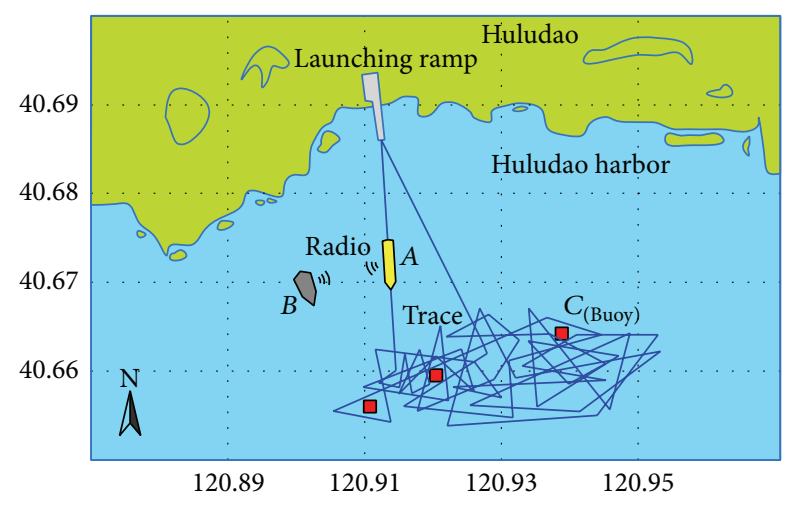

FIgURE 8: Voyage map of sea trial.

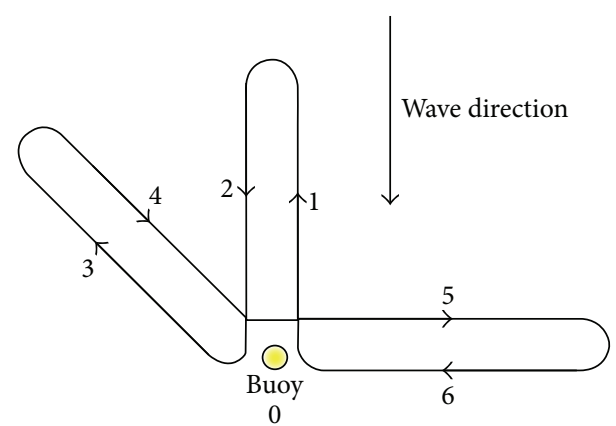

FIGURE 9: Nominal sailing pattern.

direction 3 is for port quarter condition, direction 4 is for starboard bow condition, direction 5 is for port beam condition, and direction 6 is for starboard beam condition.

\section{Sea State Estimation}

It is essential to estimate the sea state model encountered because the load and motion responses are induced by the sea waves. Sea waves were measured using a wave buoy meter. During the measurement, wave buoy was deployed at the center of the model runs. The buoy has an axis accelerometer mounted at its COG to allow for the measurement of instantaneous vertical acceleration of wave surface.

An example of 50-second duration of the measured vertical acceleration of wave surface is given in Figure 10(a). To process the obtained time-domain data, spectral analysis was done using a program code based on autocorrelation function method. The autocorrelation function based theory considers the wave signal to be linear and stationary. The spectral result can be derived according to the probability theory, and detailed information about this method can be found in [22]. The significant wave height and characteristic period are also acquired from the spectral analysis. The wave spectrum obtained by possessing a measured 15-minute acceleration data is shown in Figure 10(b). As seen from the result, there are two dominant frequency components in the waves. The peak frequency of first dominant component is $0.252 \mathrm{~Hz}$ and the second is $0.527 \mathrm{~Hz}$. The significant wave height and period calculated by the above-mentioned spectral analysis method are $0.266 \mathrm{~m}$ and $1.932 \mathrm{~s}$, respectively. The significant wave height and period, respectively, correspond to $6.65 \mathrm{~m}$ and 9.66 s of ship prototype, which is about six-level sea state for full-scale ship.

\section{Results and Analyses}

5.1. Impact Hammer Test. Impact hammer tests were performed after the model was launched in a relative calm sea area in order to obtain the natural vibration frequencies of the ship model in wetted condition. It is noted that the target two-node natural frequency for vertical bending mode of the model hull in wetted condition is $2.316 \mathrm{~Hz}$. The stress time histories measured by strain gauges at the 4 th and 8 th stations during a hammer test are shown in Figure 11(a). As seen from the curves, there exist some low frequency load components caused by waves since the sea surface was not absolutely calm, but this has little influence on the result. The frequencydomain results shown in Figure 11(b) are obtained by fast Fourier transform (FFT) processing. As seen from the spectral results, vertical natural vibration frequencies of the first three modes of the model in wetted condition are $2.273 \mathrm{~Hz}$, $6.566 \mathrm{~Hz}$, and $11.364 \mathrm{~Hz}$, respectively. The experimental result and the prediction are in a good agreement with an error of $1.86 \%$ for the two-node vertical vibration frequency. The horizontal vibration frequencies are obtained by the same method. The two-node and three-node horizontal vibration frequencies are $4.922 \mathrm{~Hz}$ and $9.974 \mathrm{~Hz}$, respectively.

5.2. Voyage Process Overview. The sea trial was conducted at Huludao harbor of China on August 26, 2015. The model was launched at 11:40 a.m. and was taken back at 3:50 p.m. The analyses of the measured data were done as a postvoyage process. The loads, pressures, accelerations, and motions data recorded during the overall trial process are summarized in Figure 12.

The VBM and HBM loads measured at cut stations from station 2 to station 12 are displayed from bottom to top in Figures 12(a) and 12(b), respectively. The impact pressure data recorded by gauges 1 4 (locations are shown in Figure 2) are shown in Figure 12(c). Vertical axis accelerations at bow and stern areas are shown in Figure 12(d). Pitch and vertical speed at COG of the model are shown in Figures 12(e) and 12(f), respectively. It should be noted that the curves of loads, accelerations, and motions oscillate from a positive maximum to a negative minimum around the zero-mean value. The pressure values at initial and final regions of the time serieswhich are without the occurrence of water impact-are zero. However, in order to save space and for the convenience of comparison, the signals of the same category are presented together in each figure. The experimental results presented in this paper are all given corresponding to model scale.

From 0 to $3215 \mathrm{~s}$ the model was being transported and was still on the ground, which can be clearly seen from the responses shown in the figures. After the model was launched into the sea, the wave-induced responses were initially small because the waves near the beach were relatively small. As the model started to sail away from the beach, load and motion responses increased gradually. At the time of about $5600 \mathrm{~s}$, 


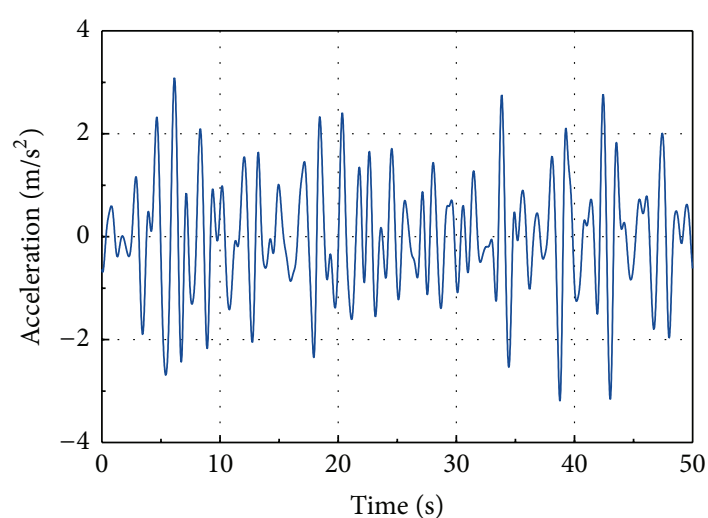

(a) Time history of vertical acceleration

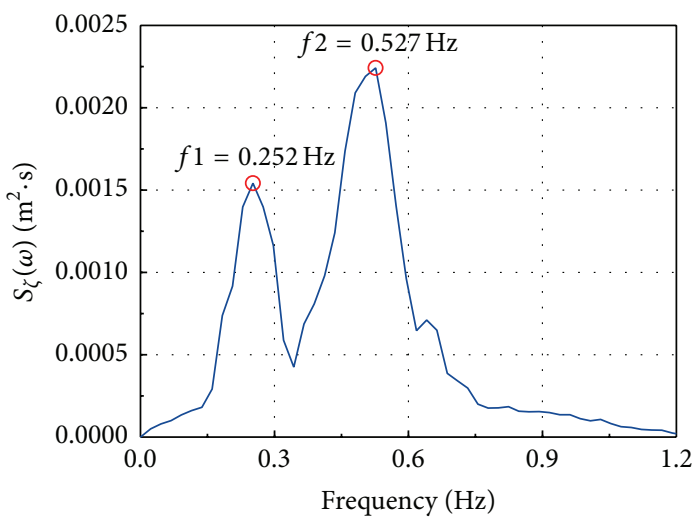

(b) Spectral analysis result

FIGURE 10: Sea waves measured and the spectral analysis result.

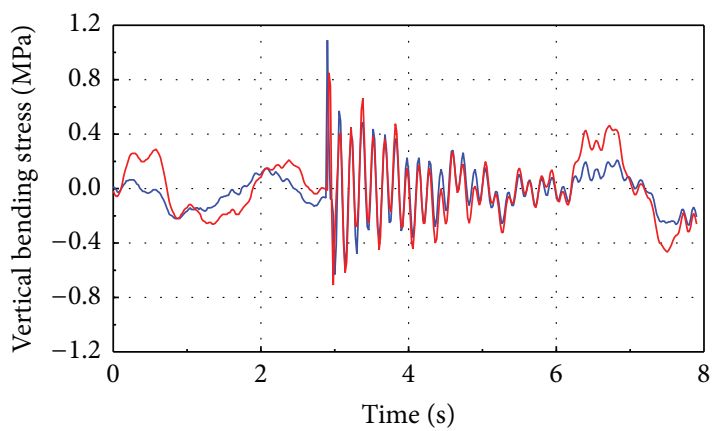

4th station

8th station

(a) Time histories of stress

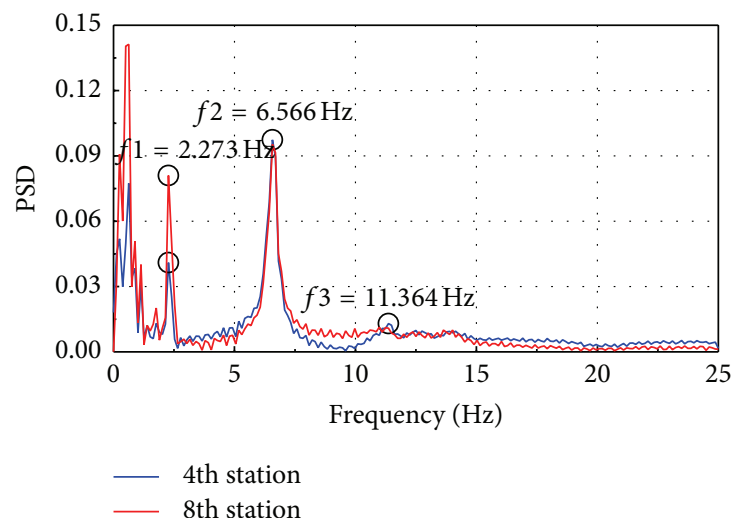

(b) Frequency-domain results

FIGURE 11: Hammer test of vertical vibrations in wetted condition.

the waves that the model experienced were steady and the tests began. Tests were finished at the time of about $12000 \mathrm{~s}$ and then the model was steered back to the coast. During the measurement, there was a break from $8500 \mathrm{~s}$ to $9000 \mathrm{~s}$. Meanwhile, the model was stopped; thus the responses were relatively small.

Typical snapshots captured from the testing video recordings are shown in Figure 13. In Figure 13(a), bow slamming phenomena are observed. It is worth mentioning that special attention should be paid to the impact loads acting on the hull caused by slamming, especially the structural strength at the bow area. Figure 13(b) presents the turning circle movement of the model during the voyage. During the tests, it was found that good propeller behavior and maneuverability of the model are of great importance in steering the model.

5.3. Short-Term Analysis. In order to investigate the shortterm responses of loads and motions of the ship model, the absolute speed and azimuth recorded by the GPS/INS device are studied firstly. Figure 14(a) illustrates the northern and eastern components of the model speed during a testing scheme period. Figure 14(b) illustrates the sailing azimuth time history of the corresponding time duration. As seen from the figures, the sailing speeds and azimuth are stable from $7500 \mathrm{~s}$ to $8500 \mathrm{~s}$. The resultant velocity is about $2 \mathrm{~m} / \mathrm{s}$, which corresponds to real ship speed of 19 knots. The azimuth is about $300 \mathrm{deg}$. and it is port quarter condition considering the wave dominant direction during the testing period.

It is known that the loads experienced by ships in severe waves can be split into two main categories: global wave loads and slamming loads. Usually these two kinds of loads oscillate at different frequencies. The Fourier transform provides a general method to allow for the transformation of signals from time-domain to frequency-domain. However, there are several limitations of the Fourier spectral analysis: the data processed is limited to linear and stationary signals [23]. However, many vibrational phenomena can be approximated by linear and stationary systems; thus Fourier spectral analysis is still widely used to process such data.

Load, pressure, acceleration, and motion responses in the time duration from $7500 \mathrm{~s}$ to $8500 \mathrm{~s}$ were extracted and are illustrated in Figure 15. Time histories and the corresponding spectral results by FFT using the Origin software of VBM and HBM are presented in Figures 15(a) and 15(b), respectively. Vertical acceleration time histories and the corresponding spectral results of bow and stern areas are 

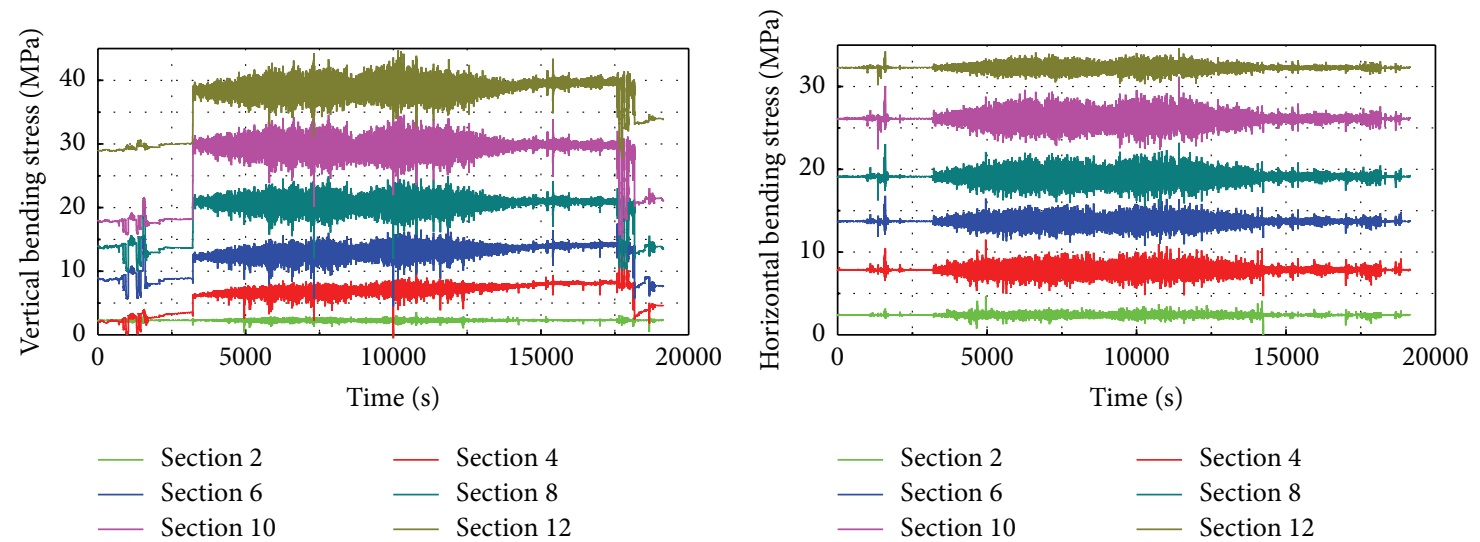

(a) VBM time histories

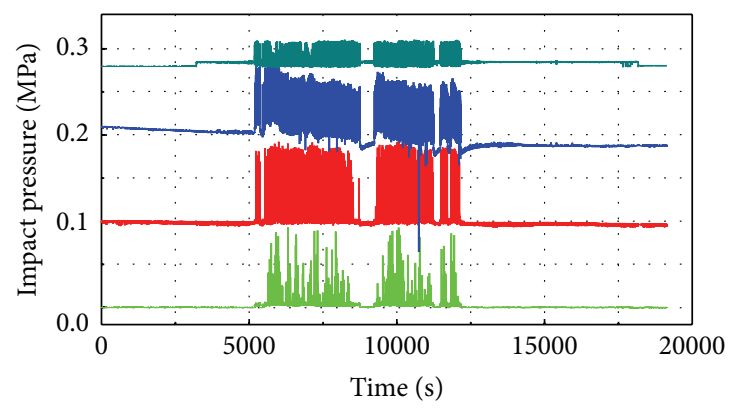

(b) HBM time histories

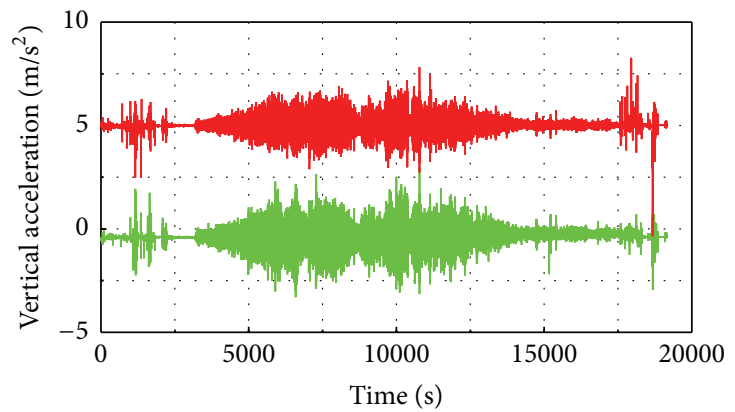

$\begin{array}{cc}\text { Gauge } 1 & \text { Gauge } 2 \\ \text { Gauge } 3 & \text { Gauge } 4\end{array}$

(c) Pressure time histories

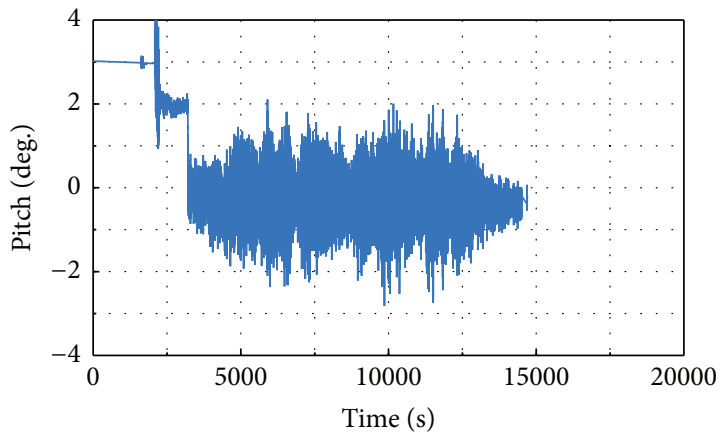

(e) Pitch time history
- Bow acceleration

_ Stern acceleration

(d) Acceleration time histories

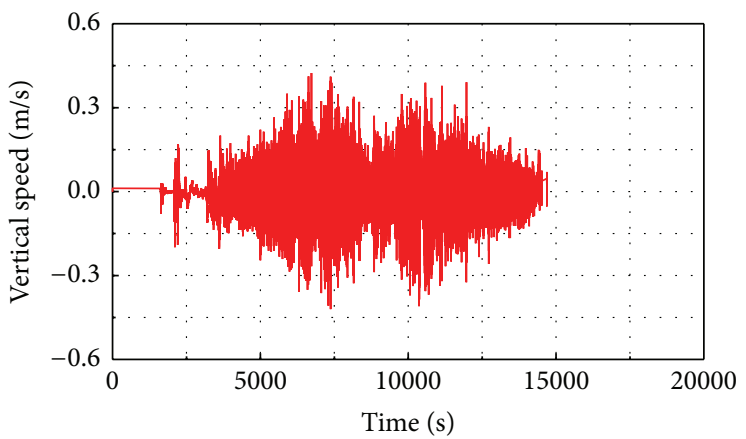

(f) Vertical speed time history

FIGURE 12: Time histories recorded during the whole trial process.

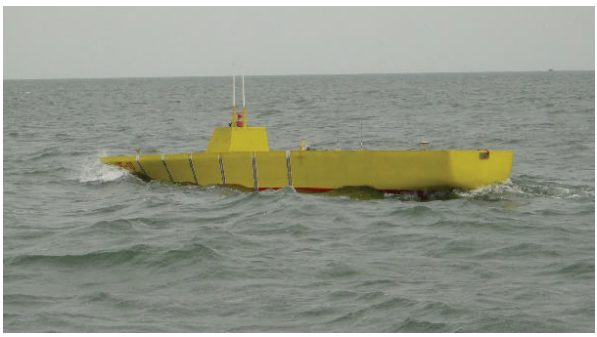

(a) Bow-flare slamming

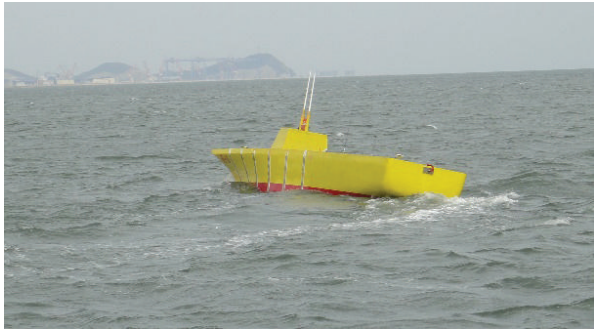

(b) Turning circle movement

FIGURE 13: Snapshots of experimental scenes. 


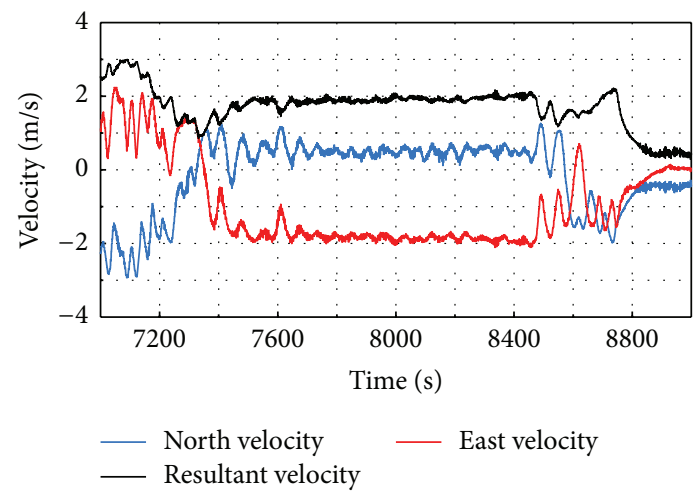

(a) Sailing speed components

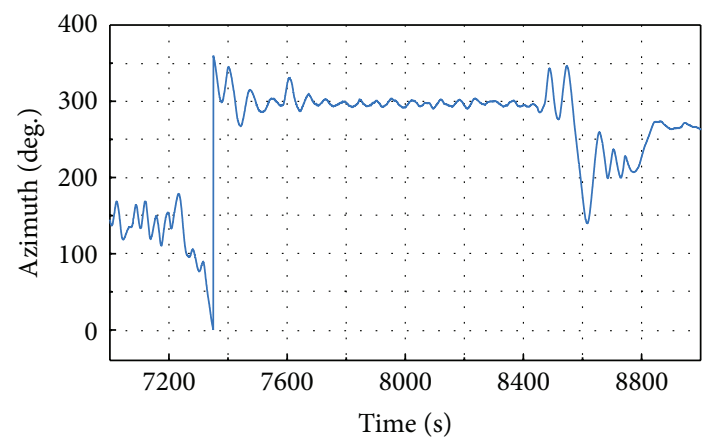

(b) Sailing azimuth

FIGURE 14: Sailing state in a short interval.

shown in Figure 15(c). Time histories and the corresponding spectral results of pitch and vertical speed at COG of the model are shown in Figures 15(d) and 15(e), respectively.

As seen from Figure 15(a), the peak frequency of VBM mainly ranges from $0.18 \mathrm{~Hz}$ to $0.92 \mathrm{~Hz}$, which is the interval of encounter frequencies of the model to the sea waves. The high frequency vibration components are mainly focused around $2.214 \mathrm{~Hz}$, which is close to the two-node natural frequency of vertical vibration. Similar phenomena are observed from the HBM results. The peak frequency of HBM mainly ranges from $0.26 \mathrm{~Hz}$ to $0.91 \mathrm{~Hz}$ and the high frequency vibrations are mainly focused around $4.87 \mathrm{~Hz}$.

The dominant peak frequencies of accelerations, pitch, and vertical speed are $0.608 \mathrm{~Hz}, 0.605 \mathrm{~Hz}$, and $0.605 \mathrm{~Hz}$, respectively. The peak frequencies of longitudinal motions show good agreement. This indicates that the nonlinearity of the motions is not as pronounced as that of the loads. It is noteworthy that there exist high frequency components at the frequency of $2.214 \mathrm{~Hz}$ in the acceleration spectral results. This indicates that the vibrations of ship model have an influence on hull accelerations.

Autocorrelation function based spectral processing of the measured time series was conducted to obtain the significant amplitude values. Furthermore, extreme amplitude values during this testing period were extracted for comparative analysis. The calculated and statistical results of load and motion responses are listed in Tables 3 and 4, respectively.

It can be found from the analysis result in Table 3 that maximum values of both significant and extreme VBM
TABLE 3: Statistical results of load responses.

\begin{tabular}{lcccc}
\hline \multirow{2}{*}{ Station } & \multicolumn{2}{c}{ VBM $(\mathrm{N} \cdot \mathrm{m})$} & \multicolumn{2}{c}{ HBM $(\mathrm{N} \cdot \mathrm{m})$} \\
& Significant & Extreme & Significant & Extreme \\
\hline 2 & 145.75 & 759.08 & 149.61 & 909.75 \\
4 & 441.19 & 2254.84 & 593.17 & 2417.95 \\
6 & 1135.55 & 3905.20 & 1041.48 & 3336.92 \\
8 & 1778.70 & 4484.52 & 1507.58 & 4045.04 \\
10 & 2195.59 & 5242.68 & 1806.60 & 3942.15 \\
12 & 2204.77 & 5363.66 & 1058.58 & 1955.84 \\
\hline
\end{tabular}

TABLE 4: Statistical results of motion responses.

\begin{tabular}{lcc}
\hline Item & Significant & Extreme \\
\hline Bow acceleration $\left(\mathrm{m} / \mathrm{s}^{2}\right)$ & 1.28 & 2.42 \\
Stern acceleration $\left(\mathrm{m} / \mathrm{s}^{2}\right)$ & 0.92 & 1.88 \\
Pitch (deg.) & 0.96 & 1.85 \\
Vertical velocity $(\mathrm{m} / \mathrm{s})$ & 0.18 & 0.35 \\
\hline
\end{tabular}

occurred at station 12 , which is nearest to the longitudinal COG of model. Both significant and extreme VBM values increase from station 2 at bow area to station 10 at amidships area gradually. The same conclusion can be made from the sectional HBM and the largest sectional HBM occurred at 10th station. It is worth mentioning that the HBM loads are nearly as large as VBM loads when the ship is sailing in severe oblique waves. So enough attention should also be paid to the horizontal strength of ships at ship design stage.

To analyze the ratios of extreme value to significant value of different responses, graphical representations of the calculated ratios are shown in Figure 16. As seen from the result, the ratio of loads decreases from bow area to amidships area for both VBM and HBM. This can be explained by the fact that the instantaneous slamming loads are more likely to take place at bow area than amidships area. However, the ratios of the four motion responses range in a narrow interval from 1.89 to 2.04 . The results indicate that the nonlinear slamming effects have more influence on loads than motions.

5.4. Extremely Short-Term Analysis. In order to describe the impact and vibrational dynamic responses of the ship after encountering an oncoming wave impact, pressure and vibrational responses in extremely short-term duration are investigated in particular. Figure 17 shows the time histories of impact pressure and the corresponding VBM at the 2nd station when encountering several wave impact events. As seen from Figure 17(a), pressure gauge 3 impacted the waves seven times during the time period from $8162 \mathrm{~s}$ to $8172 \mathrm{~s}$. A severe flare slamming occurred between $8166 \mathrm{~s}$ and $8167 \mathrm{~s}$; meanwhile, all of the three gauges impacted the oncoming wave. Gauges 2 and 3 contacted with the wave, respectively, at the times of $8166.32 \mathrm{~s}$ and $8166.36 \mathrm{~s}$, and the impact lasted for about $0.5 \mathrm{~s}$. At the time of $8166.58 \mathrm{~s}$, gauge 1 contacted with the wave and the impact lasted for about $0.2 \mathrm{~s}$. For this slamming event, the recorded peak pressures at positions 1 3 are $42.37 \mathrm{kPa}, 83.83 \mathrm{kPa}$, and $64.21 \mathrm{kPa}$, respectively. The result 

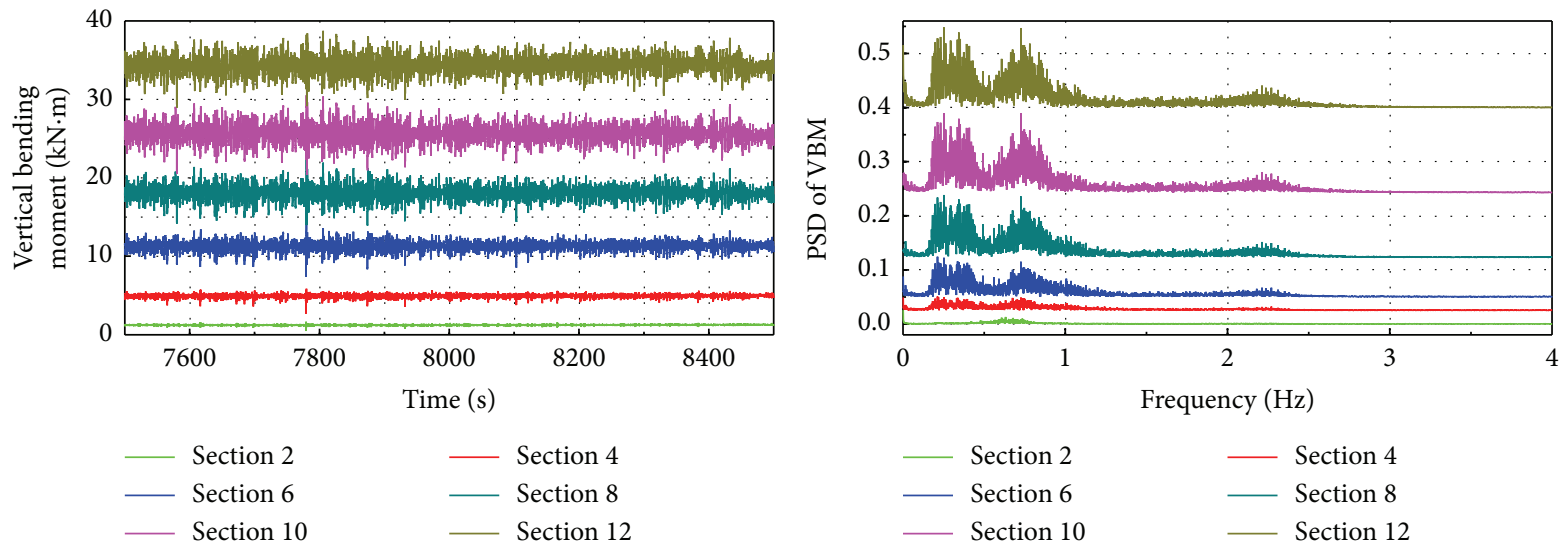

(a) Time and frequency series of VBM
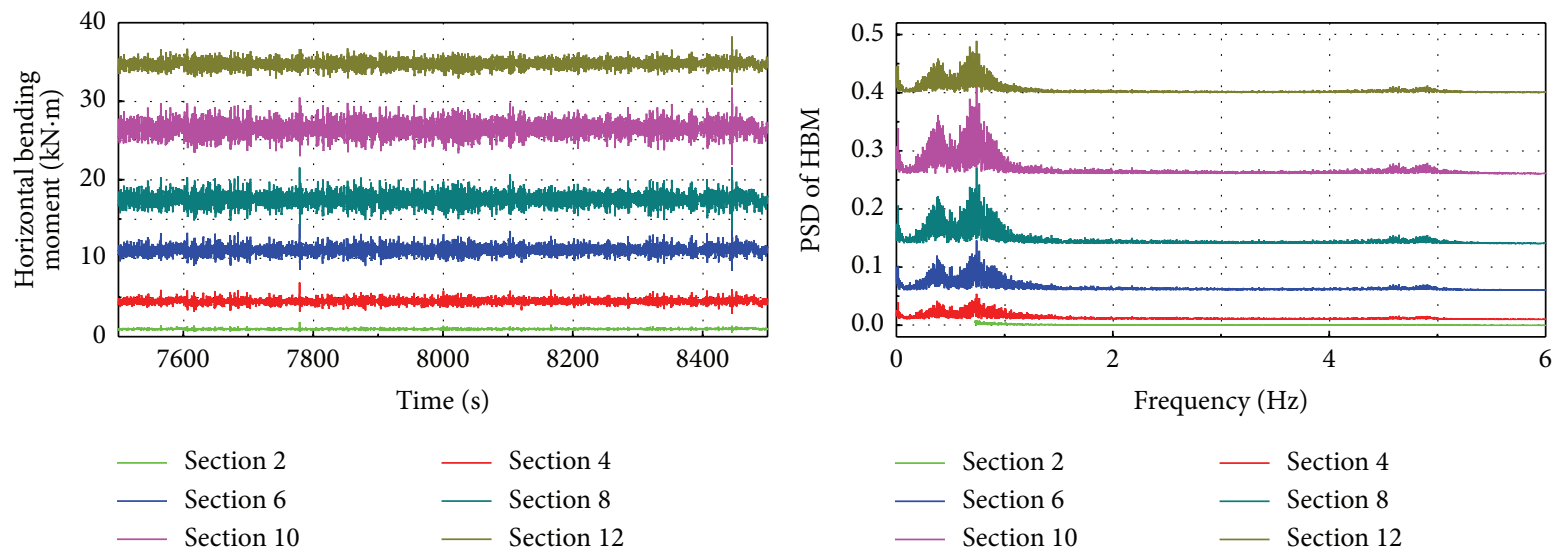

$\begin{array}{ll}- \text { Section } 2 & - \text { Section } 4 \\ \text { Section } 6 & - \text { Section } 8 \\ \text { Section } 10 & - \text { Section } 12\end{array}$

(b) Time and frequency series of HBM
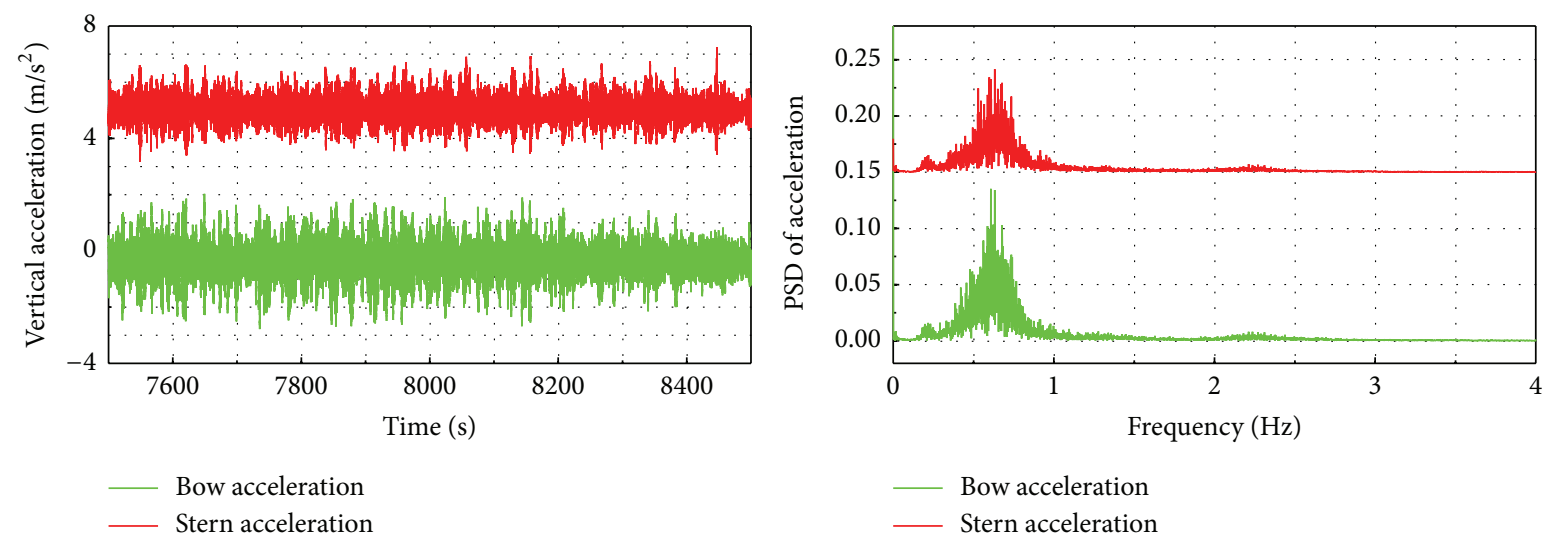

(c) Time and frequency series of accelerations
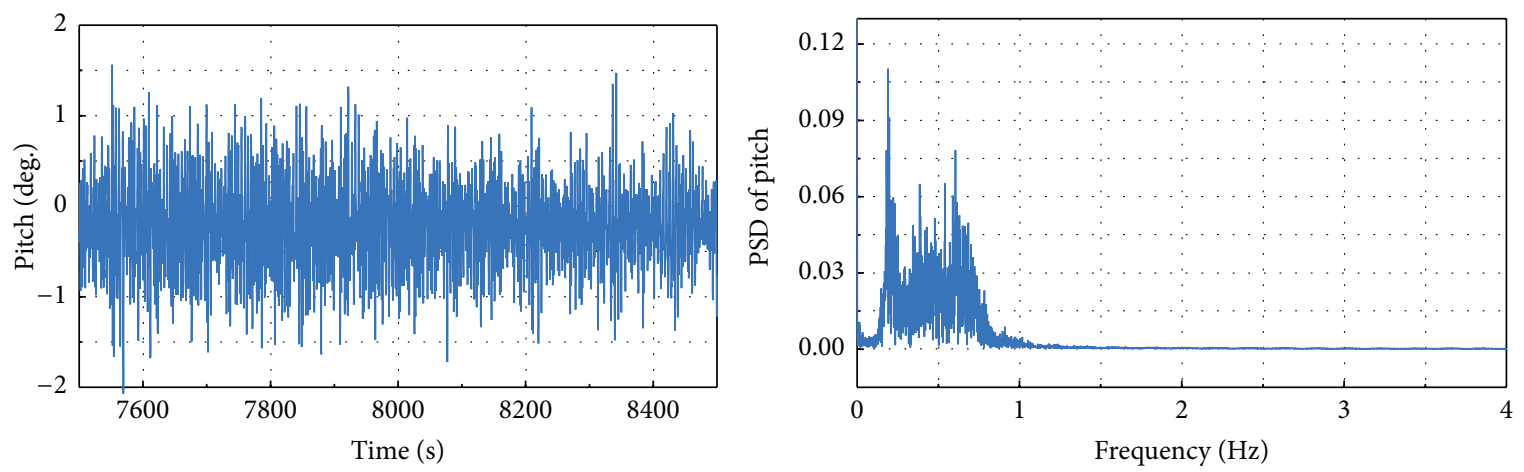

(d) Time and frequency series of pitch

FIgURE 15: Continued. 

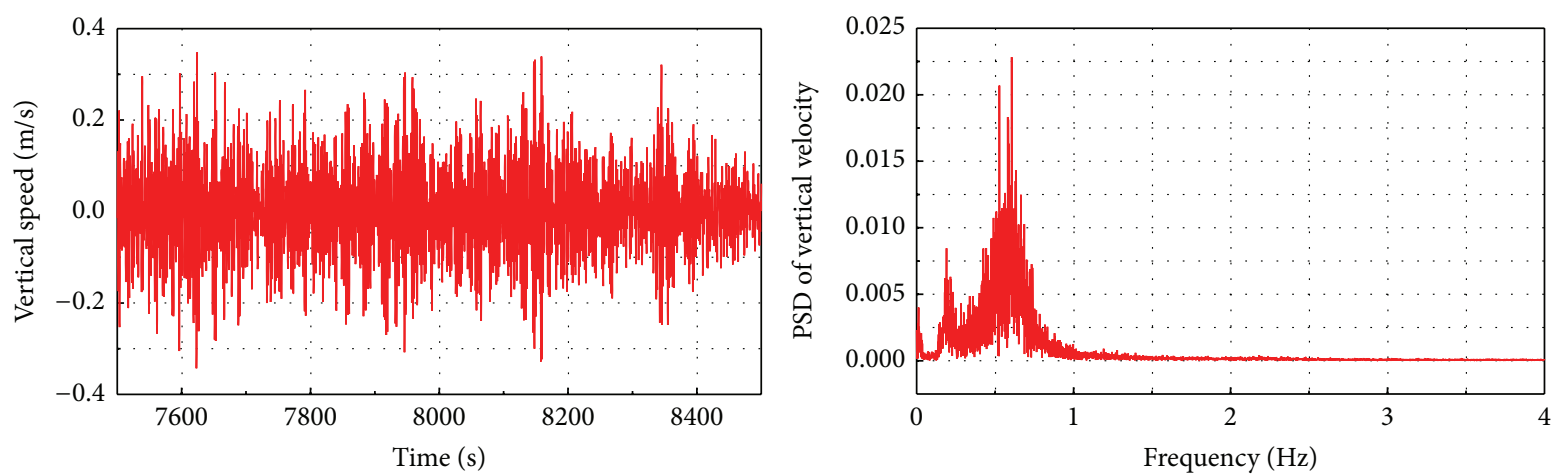

(e) Time and frequency series of vertical speed

FIGURE 15: Time series in a short interval and the corresponding spectral results.

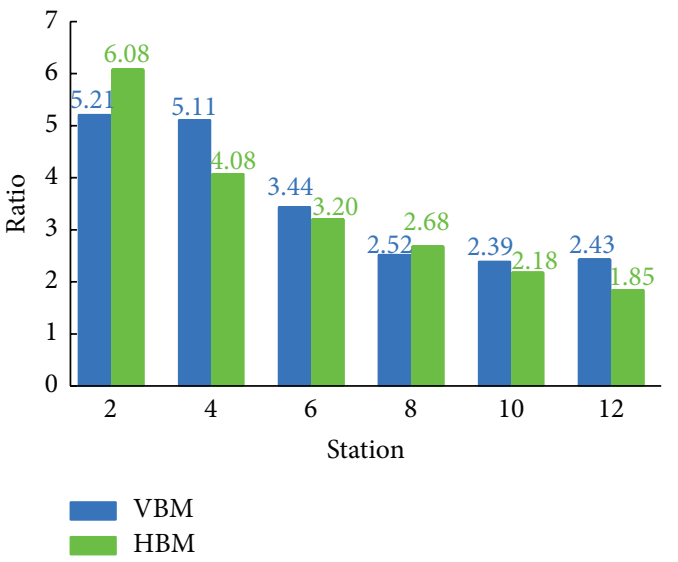

(a) Load ratios

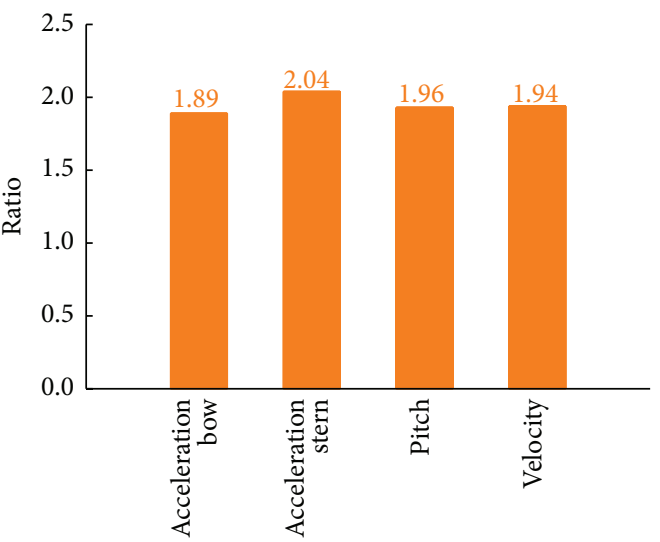

(b) Motion ratios

FIGURE 16: Ratios of extreme value to significant amplitude value.

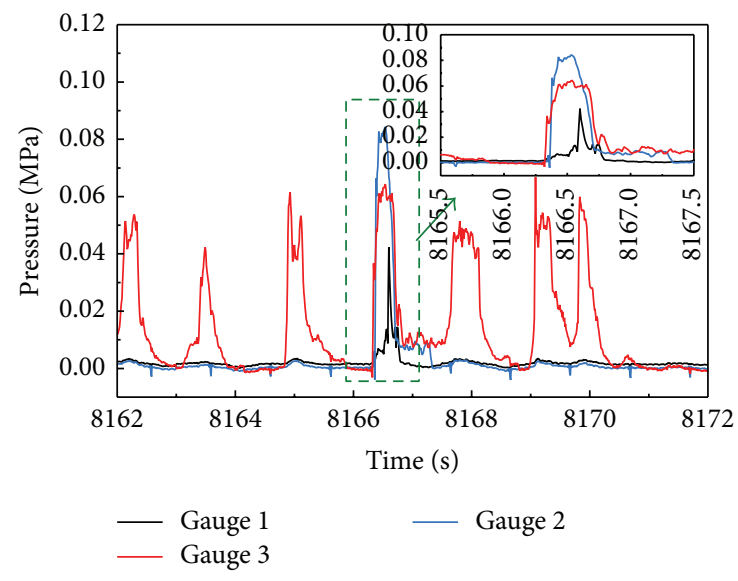

(a) Pressures of gauges 1 to 3

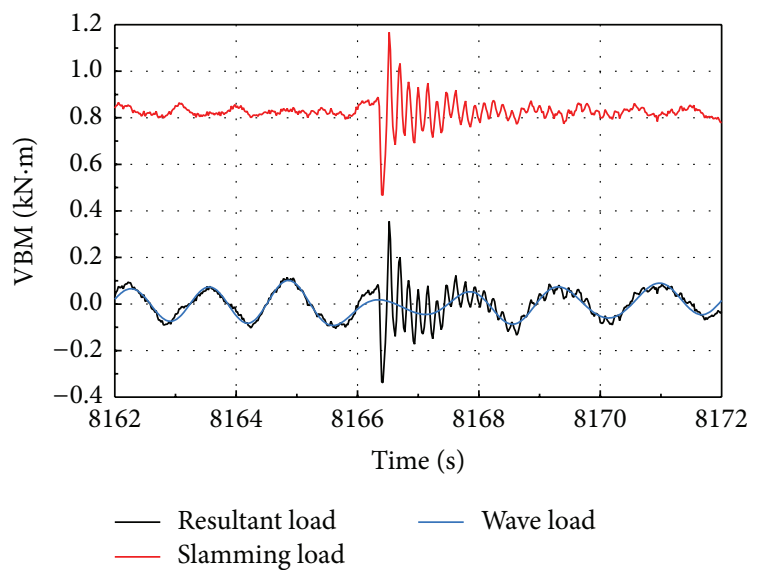

(b) VBM of station 2

FIGURE 17: Time histories of pressures and loads in an extremely short interval.

indicates that the largest slamming pressure occurred at around the position of gauge 2 for this slamming event.

As seen from Figure 17(b), a whipping phenomenon happened on the backbone due to flare slamming at the time of $8166.33 \mathrm{~s}$ and it lasted for about $3 \mathrm{~s}$. As seen from the result, the resultant loads of the ship in severe seas are composed of low frequency wave loads and high frequency slamming loads. The FFT filter is used to decompose the load components from the total loads. It can be seen from the analysis result that the amplitude value of wave frequency load before 

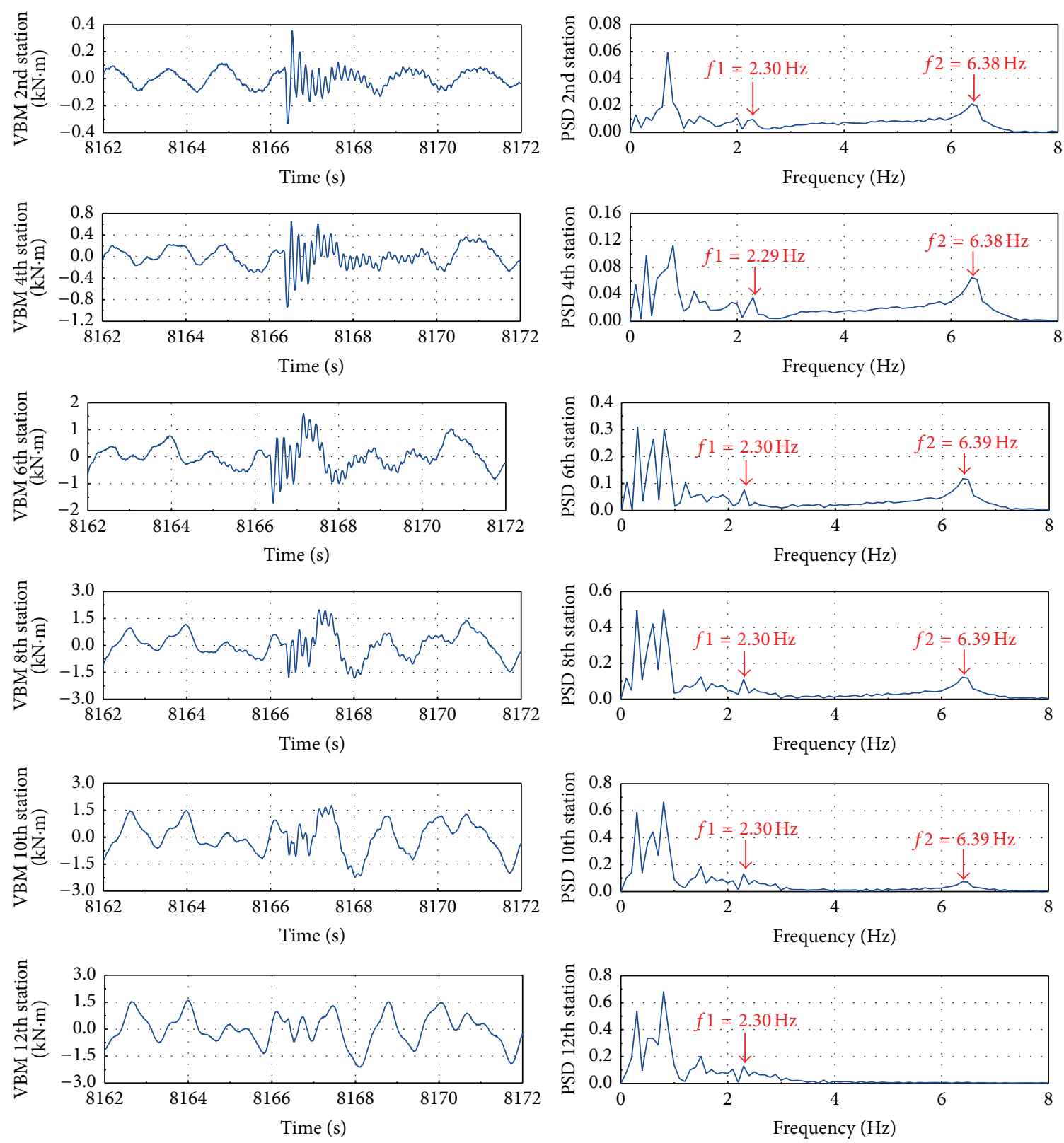

Figure 18: Time and frequency series of VBM at different stations.

the slamming occurrence is about $91.69 \mathrm{~N} \cdot \mathrm{m}$. However, the slamming load has reached $335.35 \mathrm{~N} \cdot \mathrm{m}$, which is 3.66 times of the wave component load.

The measured VBM loads from station 2 to station 12 between $8162 \mathrm{~s}$ and $8172 \mathrm{~s}$ and the corresponding spectral results are shown in Figure 18. As seen from the measured time histories, the proportion of slamming load to total load decreases from bow area to amidships area; that is, the slamming loads are pronounced at 2 nd station while they almost disappeared at 12th station. The same phenomenon can be also found from the spectral results. As seen from the spectral results, the dominant slamming components of the first five stations are all around $6.38 \mathrm{~Hz}$, which is close to the threenode natural frequency of the ship model. The subdominant slamming components of the six stations are all around $2.29 \mathrm{~Hz}$, which is close to the two-node natural frequency of the ship model. It is worth mentioning that the twonode vibrations are pronounced all along from 2 nd station to 12 th station. However, the three-node vibration components decrease from bow station to amidships station. This can be interpreted by the distributions of modal shapes along the ship. The frequencies of the wave-induced load components mainly range from $0.3 \mathrm{~Hz}$ to $0.8 \mathrm{~Hz}$ for the six stations.

\section{Conclusions and Recommendations}

This paper presents a novel measurement technique for wave-induced hydroelastic vibrations of large elastic ships in 
natural environment. From the sea trial conducted and the analyses of data acquired, several conclusions can be made as follows:

(1) The sea trial performed at Huludao harbor in October 2015 indicates that the testing systems presented in this paper are competent. The testing method and systems can be extended to a wide range of ship hydrodynamic experimental research in natural environment.

(2) The HBM loads are nearly as large as VBM loads when the ship is sailing in severe oblique waves. So enough attention should also be paid to the horizontal structural strength of ships at ship design stage.

(3) Spectral analysis results show that the sectional load increases from bow station to amidships station for both VBM and HBM. However, the proportion of slamming load component to total load decreases from bow area to amidships area. Furthermore, the nonlinear slamming phenomenon has more influence on loads than motions.

(4) Severe bow impact will result in whipping responses, which may produce enormous instantaneous loads. So whipping is an issue of strength because the instantaneous slamming loads are usually very high but damp out quickly. However, the wave frequency response of the hull girder is a fatigue issue for ships because the number of wave cycles is very large during their whole lives.

From the time-domain and frequency-domain results of the sectional loads, it can be found that there are pronounced nonlinear components that are caused by slamming events. The spectral analysis methods adopted in this study are intrinsically linked to linear systems philosophy. In the future work, nonlinear and nonstationary data processing methods, such as empirical mode decomposition (EMD) based methods, will be developed to deal with the load data.

In this work, only one typical sailing condition from the voyage trial regarding vibrational and slamming characteristics of the ship is reported. However, the experimental method proposed and data analysis results in this paper provide a general research approach for the investigation of hydrodynamic performance of ships in natural conditions. Other kinds of standard hydrodynamic tests can be conducted by the large-scale model testing system, for instance, resistance, seakeeping, propulsion, maneuverability, and stability tests, by fitting the corresponding testing equipment. These kinds of tests can be performed in both calm water lakes and coastal wave seas.

The advantages of performing ship hydrodynamic tests by using large-scale model in natural environments are obvious. For example, the errors induced by difference of Reynolds number can be reduced by using larger models when performing ship resistance tests. In addition, the sailing routes can be designed regardless of the model speed and size when performing rapidity and maneuverability tests since the natural water surface is large enough. However, there are still problems and difficulties that need further addressing in respect of this novel testing approach. For example, in some weather conditions the speed and heading of largescale model are not easy to control and adjust. Moreover, the large-scale model tests are expensive to perform and the time consumed is much longer than in a laboratory basin.

\section{Conflict of Interests}

The authors declare that there is no conflict of interests regarding the publication of this paper.

\section{Acknowledgments}

The authors would like to thank Technical Engineer Zhao Xiaodong and all the master students at the INOM of HEU, who took part in the 2015-year sea trial activities, for their kind help during the preparation and conduction of the tests. This work was partially supported by the National Natural Science Foundation of China (no. 51079034). The authors would like to express their gratitude to the foundation.

\section{References}

[1] S. Ivo, M. Sime, and T. Stipe, "Investigation of ship hydroelasticity," Ocean Engineering, vol. 35, no. 5-6, pp. 523-535, 2008.

[2] S. E. Hirdaris, W. Bai, D. Dessi et al., "Loads for use in the design of ships and offshore structures," Ocean Engineering, vol. 78, pp. 131-174, 2014.

[3] S. E. Hirdaris and P. Temarel, "Hydroelasticity of ships: recent advances and future trends," Proceedings of the Institution of Mechanical Engineers Part M: Journal of Engineering for the Maritime Environment, vol. 223, no. 3, pp. 305-330, 2009.

[4] G. J. Grigoropoulos and G. M. Katsaounis, "Measuring procedures for seakeeping tests of large-scaled ship models at sea," in Proceedings of the 13th IMEKO TC4 Symposium on Measurements for Research and Industrial Applications, pp. 135139, Athens, Greece, September-October 2004.

[5] A. Maron and G. Kapsenberg, "Design of a ship model for hydro-elastic experiments in waves," International Journal of Naval Architecture and Ocean Engineering, vol. 6, no. 4, pp. 11301147, 2014.

[6] J. L. Jiao, H. L. Ren, H. Yang, and D. L. Mao, "Design of channelsection backbone of segmented model for wave loads experiment," Journal of Vibration and Shock, vol. 34, no. 14, pp. 11-15, 2015.

[7] J. R. Lin, S. L. Zheng, Y. Sun, and Y. J. Zhang, "Experimental techniques of the continued elastic model," Shipbuilding of China, vol. 2, pp. 63-71, 1992.

[8] Z. Y. Chen, H. L. Ren, H. Li, and X. Zhao, "The wave load experimental investigation of a segmented model of a very large ship based on variable cross-section beams," Journal of Harbin Engineering University, vol. 33, no. 3, pp. 263-268, 2012.

[9] G. Thomas, S. Winkler, M. Davis et al., "Slam events of highspeed catamarans in irregular waves," Journal of Marine Science and Technology, vol. 16, no. 1, pp. 8-21, 2011.

[10] Z.-Y. Chen, H.-L. Ren, H. Li, and K.-H. Zhang, "Experimental and numerical analysis of bow slamming and whipping in different sea states," Journal of Ship Mechanics, vol. 16, no. 3, pp. 246-253, 2012

[11] The Seakeeping Committee, "Final report and recommendations to the 26th ITTC", in Proceedings of the 26th International 
Towing Tank Conference, vol. 1, Rio de Janeiro, Brazil, September 2011.

[12] The Seakeeping Committee, "Final report and recommendations to the 27th ITTC," in Proceedings of the 27th International Towing Tank Conference, vol. 1, Copenhagen, Denmark, AugustSeptember 2014.

[13] S. Z. Sun, H. L. Ren, X. D. Zhao, and J. D. Li, "Experimental study of two large-scale models seakeeping performance in coastal waves," Brodogradnja, vol. 66, no. 2, pp. 47-60, 2015.

[14] A. Coraddu, G. Dubbioso, S. Mauro, and M. Viviani, "Analysis of twin screw ships' asymmetric propeller behaviour by means of free running model tests," Ocean Engineering, vol. 68, pp. 4764, 2013.

[15] F. Fossati, I. Bayati, F. Orlandini et al., "A novel full scale laboratory for yacht engineering research," Ocean Engineering, vol. 104, pp. 219-237, 2015.

[16] J. L. Jiao, H. L. Ren, and C. A. Adenya, "Experimental and numerical analysis of hull girder vibrations and bow impact of a large ship sailing in waves," Shock and Vibration, vol. 2015, Article ID 706163, 10 pages, 2015.

[17] G. Jacobi, G. Thomas, M. R. Davis, and G. Davidson, "An insight into the slamming behaviour of large high-speed catamarans through full-scale measurements," Journal of Marine Science and Technology, vol. 19, no. 1, pp. 15-32, 2014.

[18] S.-Z. Sun, J.-D. Li, X.-D. Zhao, J.-L. Luan, and C.-T. Wang, "Remote control and telemetry system for large-scale model test at sea," Journal of Marine Science and Application, vol. 9, no. 3, pp. 280-285, 2010.

[19] J. L. Jiao, H. L. Ren, S. Z. Sun, and C. A. Adenya, "Investigation of a ship's hydroelasticity and seakeeping performance by means of large-scale segmented self-propelling model sea trials," Journal of Zhejiang University-SCIENCE A, In press.

[20] GARMIN, GHP 12 Installation Instructions, Garmin International Inc, 2011.

[21] U. D. Nielsen and D. C. Stredulinsky, "Sea state estimation from an advancing ship-a comparative study using sea trial data," Applied Ocean Research, vol. 34, pp. 33-44, 2012.

[22] Y. X. Yu, Random Wave and Its Applications to Engineering, Dalian University of Technology Press, Dalian, China, 1992.

[23] N. E. Huang, Z. Shen, S. R. Long et al., "The empirical mode decomposition and the Hilbert spectrum for nonlinear and non-stationary time series analysis," The Royal Society of London: Proceedings Series A: Mathematical, Physical and Engineering Sciences, vol. 454, no. 1971, pp. 903-995, 1998. 


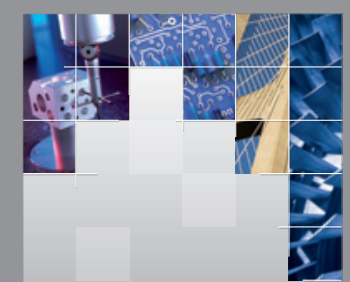

\section{Enfincering}
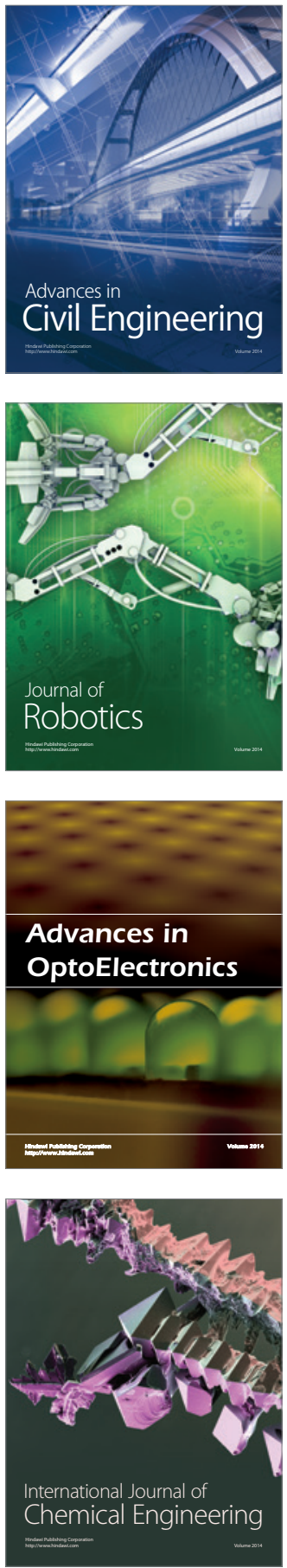

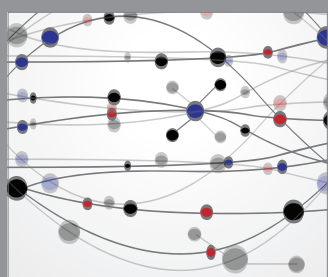

The Scientific World Journal

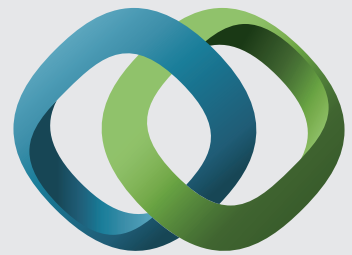

\section{Hindawi}

Submit your manuscripts at

http://www.hindawi.com
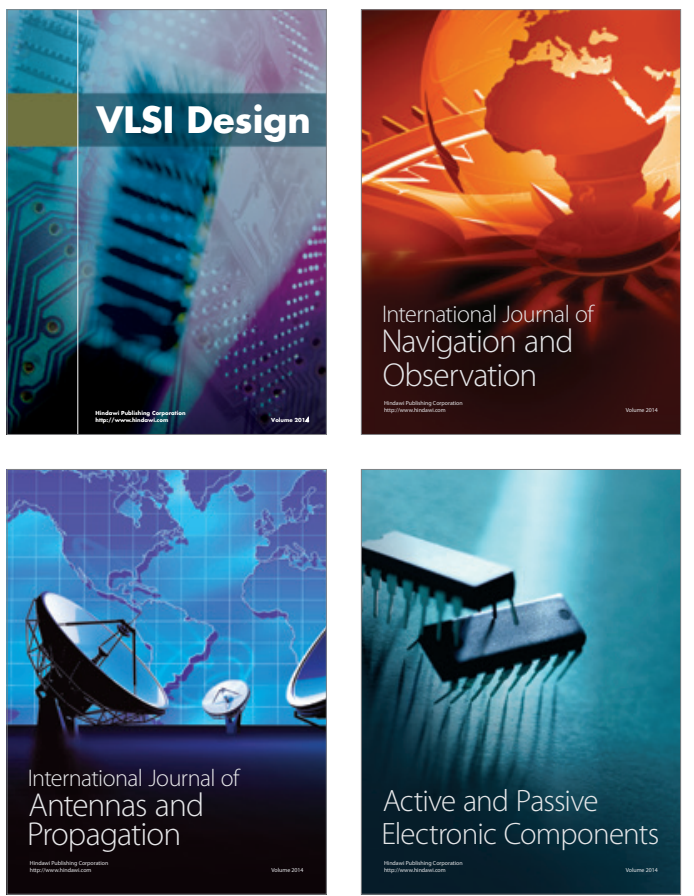
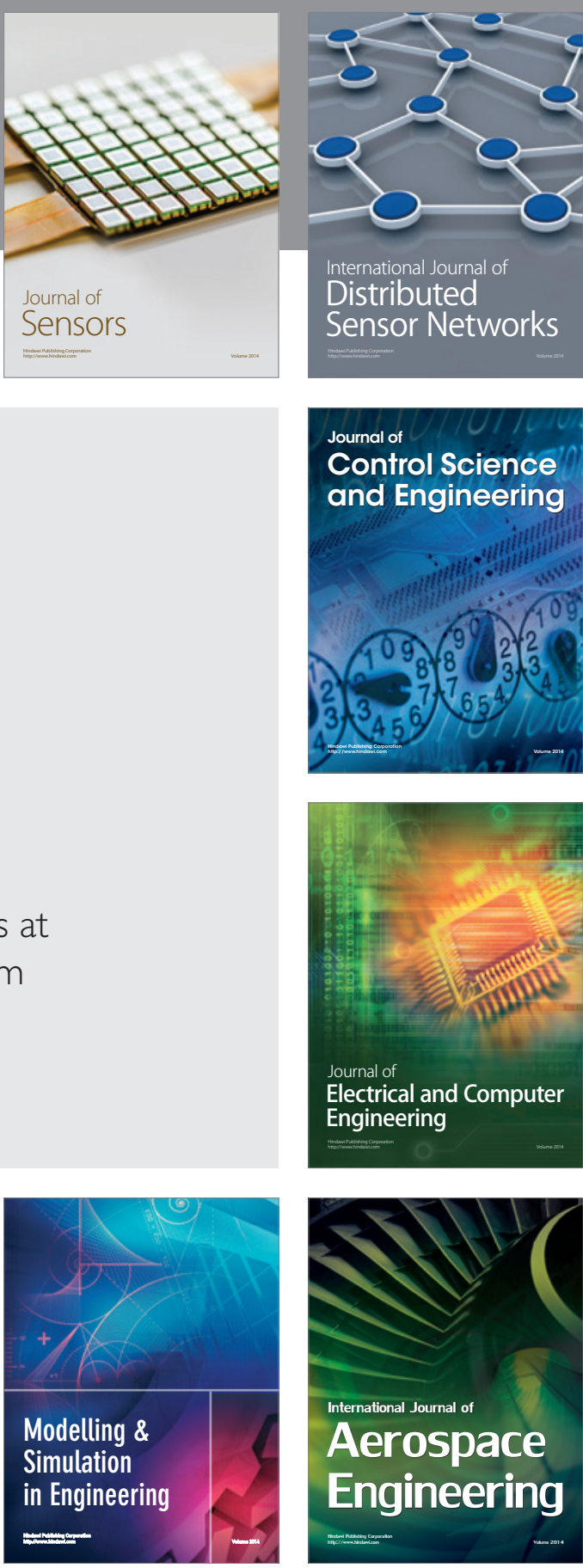

International Journal of

Distributed

Sensor Networks

Journal of

Control Science

and Engineering
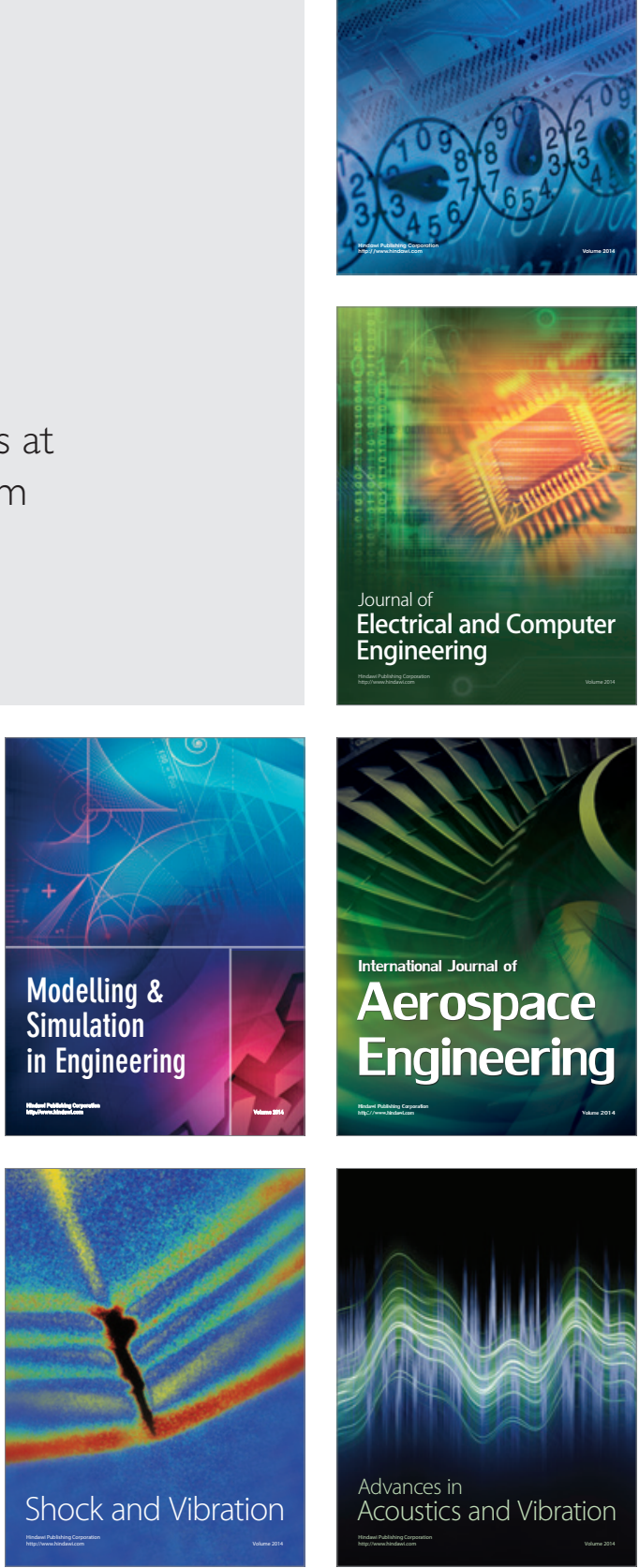